\title{
New prognostic criteria for children with cyanotic congenital heart disease
}

\author{
JOHN S H TAY, WILLIAM C L YIP \\ From University Department of Paediatrics, Singapore General Hospital, Singapore
}

SUMMARY Available oxygen and oxygen unloading capacity were determined at the time of cardiac catheterisation, from blood gas analysis, $\mathrm{p} 50$ in vivo, and haemoglobin, in 79 children with cyanotic congenital heart disease, their age ranging from 2 weeks to 14 years. The patients were followed up for six months to find out how many of those without surgical intervention survived. Actuarial analysis showed that the six month survival rate among the patients with low available oxygen or oxygen unloading capacity was significantly lower ( $24 \%$ and $49 \%$, respectively) compared with those with normal indices ( $90 \%$ and $96 \%$, respectively). Both available oxygen and oxygen unloading capacity were superior to arterial oxygen saturation and arterial oxygen content as prognostic criteria. Haemoglobin and haematocrit were of little value in prognosis. Available oxygen appeared to be the best prognostic criterion for survival at six months. It is concluded that available oxygen and oxygen unloading capacity are useful prognostic criteria in children with cyanotic congenital heart disease. These new criteria, when used in conjunction with the conventional methods of assessing the cardiac lesion, may be of considerable help to the physician in evaluating the prognosis of the patient.

Children with cyanotic congenital heart disease have considerable mortality, especially in infancy, ${ }^{1}$ if not operated on. Recent advances in cardiac surgery ${ }^{2} 3$ have made it possible to save many of these infants. In order to salvage more of them, the clinician must be able to select patients who would soon die if not operated on. This approach is particularly important if the institution has limited resources for the investigation and treatment of these patients, for example, when there is a long waiting list for surgery.

The feasibility of surgery for a particular patient is usually assessed after a complete examination, including cardiac catheterisation and angiography. Anatomical considerations are of paramount importance when assessing operability in cyanotic congenital heart disease. The assessment of the urgency of the need for surgery tends to be based also on anatomical data and the knowledge of the natural history of each anatomical subgroup. It would be useful if physiological prognostic criteria could be developed, especially if these criteria could be applied independently of detailed anatomical considerations.

In cyanotic congenital heart disease, hypoxaemia limits the amount of oxygen available to the tissues.

Accepted for publication 1 September 1981
From first principles, it appears likely that the prognosis of children with cyanotic congenital heart disease may be related to oxygen availability to the tissues. As obligatory tissue oxygen consumption in children with cyanotic congenital heart disease remains unchanged, ${ }^{4}$ the resultant decrease in oxygen to the tissues necessitates some compensatory adjustment. In serious cyanotic congenital heart disease, the ability to increase the cardiac output is often limited, and compensation mediated through haematological means becomes more important, for example, increase in red cell mass, 2,3-diphosphoglycerate (2,3-DPG) levels and in the haemoglobin-oxygen affinity, ${ }^{4-6}$ thereby helping to increase delivery of oxygen to the tissues. Two haematological indices have been developed recently to quantify oxygen availability to the tissues: oxygen unloading capacity ${ }^{7}$ and available oxygen. ${ }^{8}$

The purpose of this study is to evaluate the usefulness of oxygen unloading capacity and available oxygen as prognostic criteria in children with cyanotic congenital heart disease.

\section{Patients and methods}

All children with cyanotic congenital heart disease 
catheterised in the University Department of Paediatrics, Singapore General Hospital (from December 1976 to April 1980), form the subjects for study, which was prospective. As a policy, all children with cyanotic congenital heart disease were submitted to cardiac catheterisation. Exceptions were because the parents did not consent or there was a shortage of catheter time, with the result that some children died before cardiac catheterisation. These children were excluded from the study.

In this study there were 79 children, whose ages ranged from 2 weeks to 14 years. Haemoglobin and haematocrit were determined on the day of cardiac catheterisation. At the time of cardiac catheterisation, venous blood, obtained from the right atrium, and arterial blood, obtained from the aorta or femoral artery, were sent for blood gas analysis. (Mixed venous blood is not necessary for the purpose of the calculations below, and peripheral venous blood can also be used. $\left.{ }^{9}\right)$ Haemoglobin was measured by the Corning Eel Hemoglobinometer using the cyanmethaemoglobin method, while haematocrit was estimated by Quick Fit Micro-haematocrit Centrifuge and Microcapillary reader. Blood gases were analysed using the Corning model $165 \mathrm{pH} / \mathrm{blood}$ gas analyser. Oxygen saturation was directly estimated by American Optical Micro Reflection Oximeter.

p 50 standard, the partial pressure of oxygen when the haemoglobin is $50 \%$ saturated with oxygen under standard conditions $\left(37^{\circ} \mathrm{C}\right.$ and $\left.\mathrm{pH} 7.4\right)$, was calculated using the $\mathrm{pH}$, oxygen saturation, and oxygen tension of the venous blood. ${ }^{9} \mathrm{p} 50$ in vivo was then calculated from the $\mathrm{p} 50$ standard, correcting for $\mathrm{pH}$ and base excess measured on arterial blood. ${ }^{10}$ The next mathematical manoeuvre involved the calculation of percentage saturation of haemoglobin at an arbitrary oxygen tension of $40 \mathrm{mmHg}$ ( $\mathrm{Y} \mathrm{40}$ ) and at oxygen tension of $20 \mathrm{mmHg}$ (Y 20), employing Hill's empirical equation, 1112 with the use of $p 50$ in vivo for placement of the oxygen dissociation curve.

The oxygen unloading capacity was calculated ${ }^{7}$ from the arterial oxygen saturation, Y 40, and haemoglobin. Available oxygen was similarly calculated, ${ }^{8}$ using Y 20 instead of Y 40 . At the time of study all patients had normal body temperature. The normal levels of available oxygen and oxygen unloading capacity were taken to be above 9.6 and $2.0 \mathrm{ml} / \mathrm{dl}$, respectively. ${ }^{13} 14$

The patients were followed up for a period of six months after cardiac catheterisation to determine how many died during this period without operation. Indications for surgery were assessed using conventional criteria (since it would be unethical to withhold surgery from those who could be operated upon). The children submitted to operation were considered as "lost to follow-up", since the purpose of this project was to assess the natural history of children with cyanotic congenital heart disease in relation to oxygen unloading capacity and available oxygen. Life table analysis with maximum use of the data was carried out using the method described by Cutler and Ederer. ${ }^{15}$ The difference between two means was assessed using Student's $t$ test and the difference between two proportions was evaluated using the binomial distribution.

\section{Results}

Out of the 79 patients in this study, there were 49 children with "complete" follow up for six months (those who were not operated on and not lost to follow up): 30 remained alive at six months while 19 died during this period. Twenty-six children were operated on and only four patients were truly lost to follow up. For the purpose of analysis, the last two categories were considered to be "lost to follow up".

Table 1 shows the types of cyanotic congenital heart disease in this study. Table 2 shows the mortality on six months follow up if the patients who were "lost to follow up" were excluded. The mortality among the patients with low available oxygen or oxygen unloading capacity was much higher $(76.2 \%$ and $54.5 \%$, respectively) compared with those with normal available oxygen or oxygen unloading capacity $(10.7 \%$ and $6.3 \%$, respectively), the difference being statistically very significant $(\mathrm{p}<0.00000001$ and $\mathrm{p}<0.00001$, respectively). In contrast, mortality was not significantly higher among the children with haemoglobins of $18 \mathrm{~g} / \mathrm{dl}$ and above, or haematocrits above $65 \%$, compared with the corresponding groups ( $>0.71$ and $p>0.33$, respectively). Children with arterial oxygen saturations of $60 \%$ and below did show an increased mortality compared with those with arterial oxygen saturation above $60 \%(\mathrm{p}<0.003)$. Arterial oxygen content $(<150 \mathrm{ml} / \mathrm{l})$ was a useful prognostic criterion but not as good as available oxygen.

Actuarial analysis with maximum use of the data ${ }^{13}$ (children who were "lost to follow up" can also contribute some information) was carried out (Table 3). The children with low available oxygen, low oxygen unloading capacity, and low arterial oxygen saturation showed a significantly lower six month survival rate compared with those with normal indices $(\mathrm{p} \ll 0.001$ in all three instances). Again, arterial oxygen content was a useful prognostic criterion but inferior to available oxygen. As before, children with haemoglobin $18 \mathrm{~g} / \mathrm{dl}$ and above did not show a decreased survival rate compared with those with haemoglobins below $18 \mathrm{~g} / \mathrm{dl}(\mathrm{p}>0.70)$. Patients with haematocrits above $65 \%$ had a lower survival rate compared with those with haematocrits of $65 \%$ and below $(p<0.02)$. 
Table 1 Types of cyanotic congenital heart disease

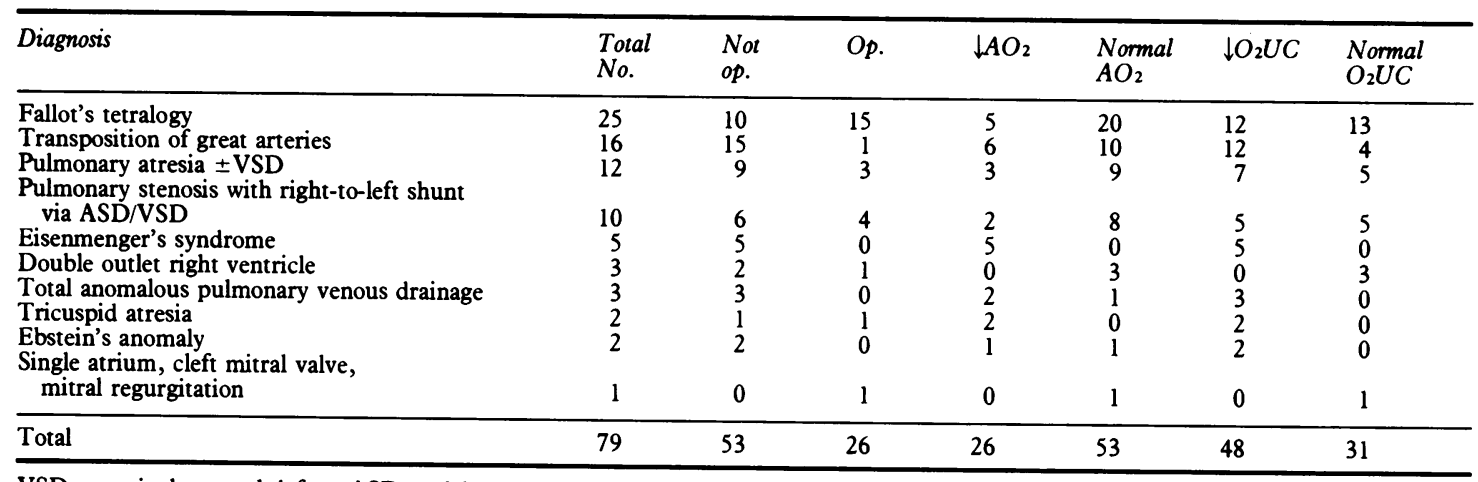

VSD, ventricular septal defect; $\mathrm{ASD}$, atrial septal defect; Op., operated; $\mathrm{AO}_{2}$, available oxygen; $\mathrm{O}_{2} \mathrm{UC}$, oxygen unloading capacity.

Table 2 Mortality on six month follow up (patients who were "lost to follow up" were excluded)

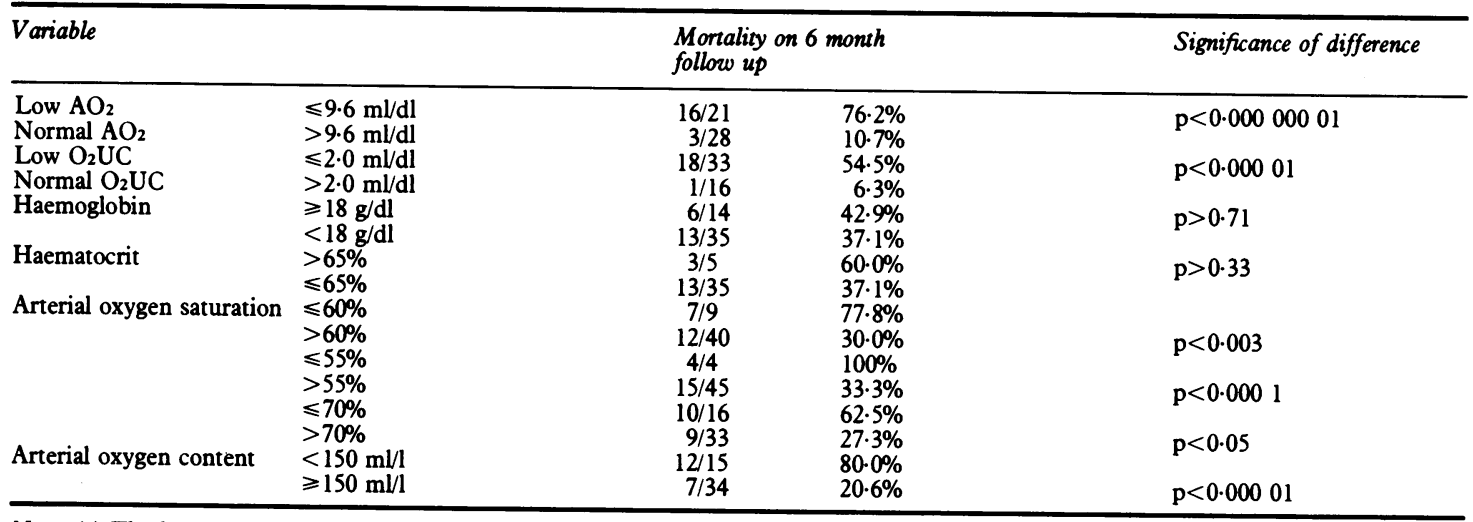

Note: (a) The haematocrit values of nine of the patients were not available.

(b) $\mathrm{AO}_{2}$, available oxygen; $\mathrm{O}_{2} \mathrm{UC}$, oxygen unloading capacity.

Table 3 Six month survival rates (actuarial analysis with maximum use of data)

\begin{tabular}{|c|c|c|c|c|c|}
\hline Variable & & No. & $\begin{array}{l}6 \text { month } \\
\text { survival rate }\end{array}$ & $\begin{array}{l}\text { Standard } \\
\text { error }\end{array}$ & $\begin{array}{l}\text { Significance of } \\
\text { difference }\end{array}$ \\
\hline $\begin{array}{l}\text { Low } \mathrm{AO}_{2} \\
\text { Normal } \mathrm{AO}_{2} \\
\text { Low } \mathrm{O}_{2} \mathrm{UC} \\
\text { Normal } \mathrm{O}_{2} \mathrm{UC} \\
\text { Haemoglobin } \\
\text { Haematocrit } \\
\text { Arterial oxygen saturation }\end{array}$ & $\begin{array}{l}\leqslant 9.6 \mathrm{ml} / \mathrm{dl} \\
>9.6 \mathrm{ml} / \mathrm{dl} \\
\leqslant 2.0 \mathrm{ml} / \mathrm{dl} \\
>2.0 \mathrm{ml} / \mathrm{dl} \\
\geqslant 18 \mathrm{~g} / \mathrm{dl} \\
<18 \mathrm{~g} / \mathrm{dl} \\
>65 \% \\
\leqslant 65 \% \\
\leqslant 60 \% \\
>60 \% \\
\leqslant 55 \% \\
>55 \% \\
\leqslant 70 \% \\
>70 \% \\
<150 \mathrm{ml} / 1 \\
\geqslant 150 \mathrm{ml} / 1\end{array}$ & $\begin{array}{r}26 \\
53 \\
48 \\
31 \\
25 \\
54 \\
10 \\
54 \\
13 \\
66 \\
9 \\
70 \\
27 \\
52 \\
23 \\
56\end{array}$ & $\begin{array}{l}0.24 \\
0.90 \\
0.49 \\
0.96 \\
0.68 \\
0.67 \\
0.57 \\
0.67 \\
0.28 \\
0.74 \\
0.19 \\
0.70 \\
0.43 \\
0.78 \\
0.23 \\
0.84\end{array}$ & $\begin{array}{l}0.11 \\
0.05 \\
0.09 \\
0.04 \\
0.14 \\
0.09 \\
0.20 \\
0.09 \\
0.16 \\
0.07 \\
1.20 \\
0.08 \\
0.35 \\
0.09 \\
0.61 \\
0.07\end{array}$ & $\begin{array}{l}t=36.78(77 d f) \\
p \ll 0.001 \\
t=27.34(77 d f) \\
p<0.001 \\
t=0.38(77 d f) \\
p>0.70 \\
t=2.57(62 \mathrm{df}) \\
p<0.02 \\
t=16.82(77 d f) \\
p \ll 0.001 \\
t=3.45(77 \mathrm{df}) \\
p=0.001 \\
t=6.71(77 \mathrm{df}) \\
p<0.001 \\
t=7.27(77 \mathrm{df}) \\
p<0.001\end{array}$ \\
\hline
\end{tabular}

Note: (a) The haematocrit results of some of the patients were not available.

(b) df, degrees of freedom; $\mathrm{AO}_{2}$, available oxygen; $\mathrm{O}_{2} \mathrm{UC}$, oxygen unloading capacity. 


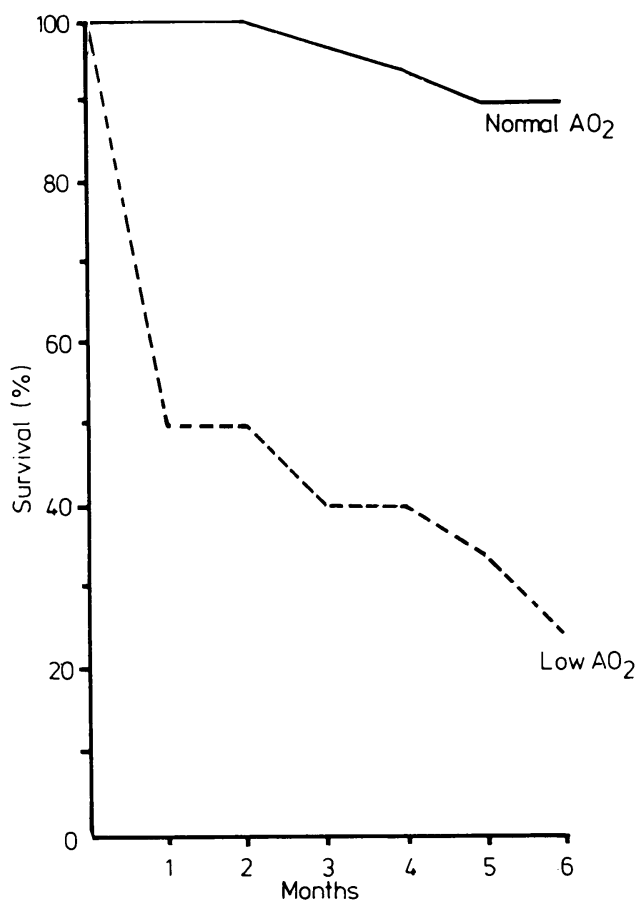

Fig. 1

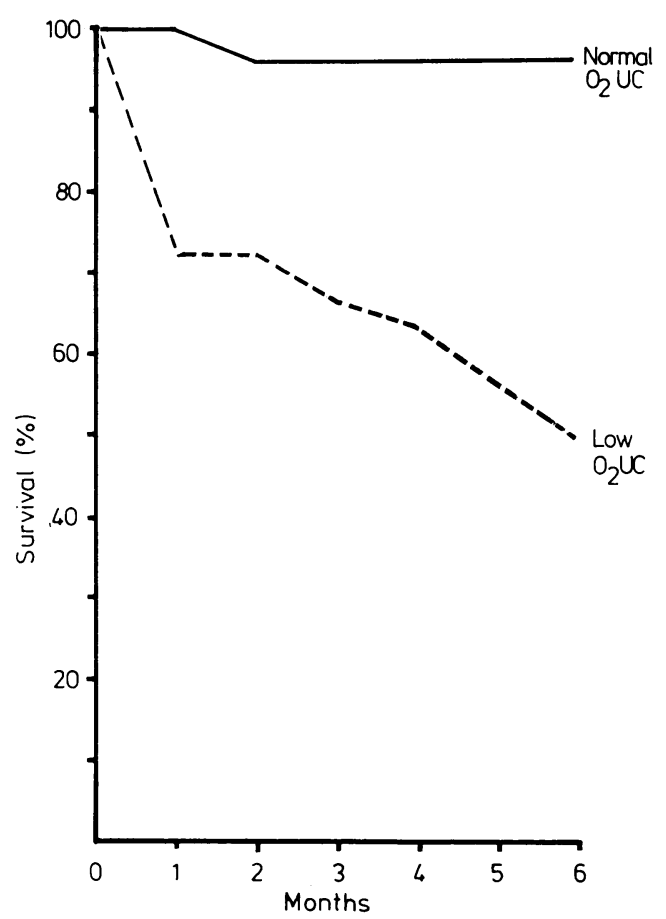

Fig. 2

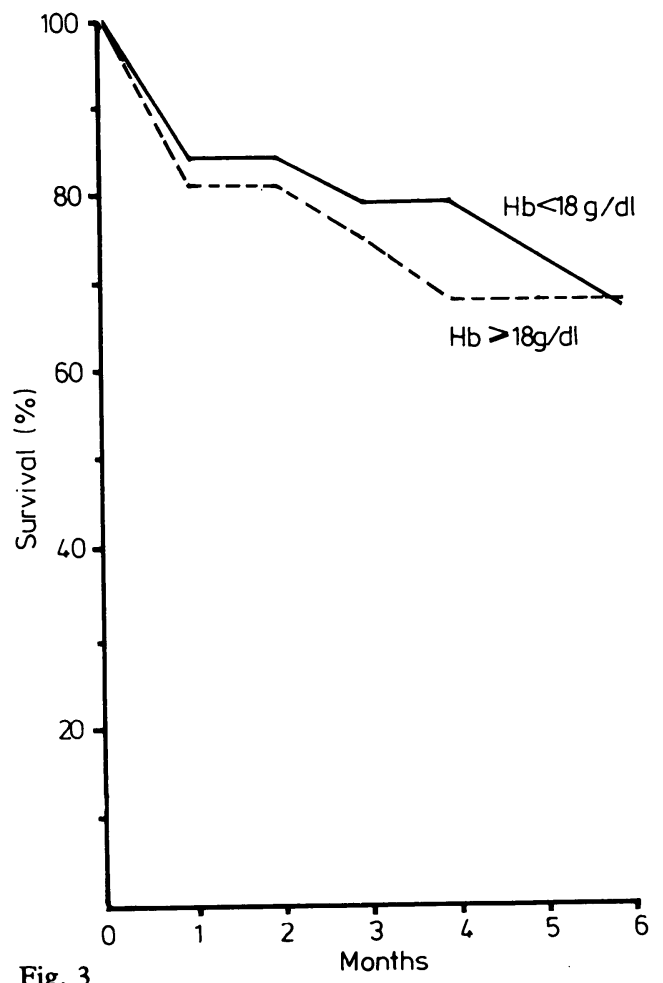

Fig. 1 Six month survival of patients with normal (>9.6 ml/dl) and low ( $\leqslant 9.6 \mathrm{ml} / \mathrm{dl}$ ) available oxygen $\left(\mathrm{AO}_{2}\right)$. Only $24 \%$ of patients with low $A O_{2}$ survived six months, in contrast to $90 \%$ of those with normal $\mathrm{AO}_{2}(p \ll 0.001)$.

Fig. 2 Six month survival of patients with normal $(>2.0 \mathrm{ml} / \mathrm{dl})$ and low $(\leqslant 2.0 \mathrm{ml} / \mathrm{dl})$ oxygen unloading capacity $\left(\mathrm{O}_{2} \mathrm{UC}\right)$. Only $49 \%$ of patients with low $\mathrm{O}_{2} \mathrm{UC}$ survived six months, in contrast to $96 \%$ of those with normal $\mathrm{O}_{2} \mathrm{UC}$ $(p \ll 0.001)$.

Fig. 3 Six month survival of patients with haemoglobin $(\mathrm{Hb})$ $\geqslant 18 \mathrm{~g} / \mathrm{dl}$ and $\mathrm{Hb}<18 \mathrm{~g} / \mathrm{dl}$. There is no significant difference between the two groups $(p>0 \cdot 70)$.

Fig. 3 


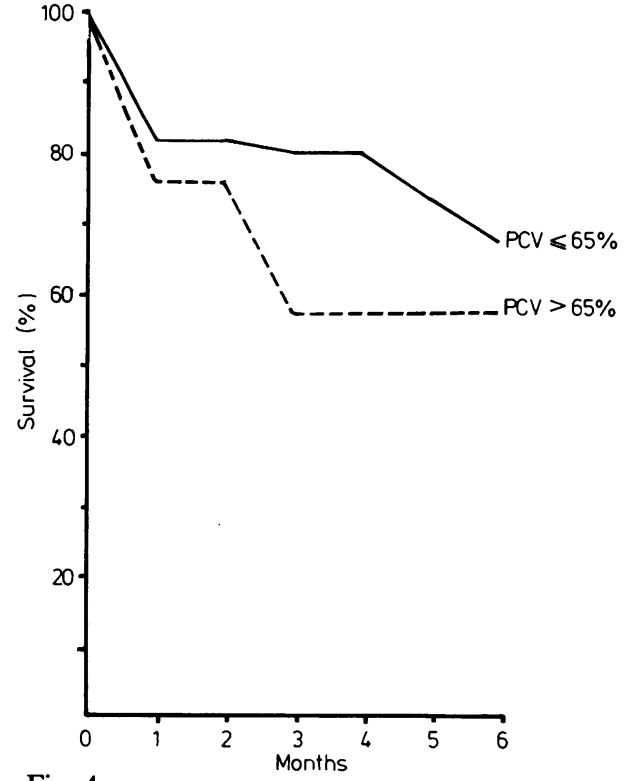

Fig. 4

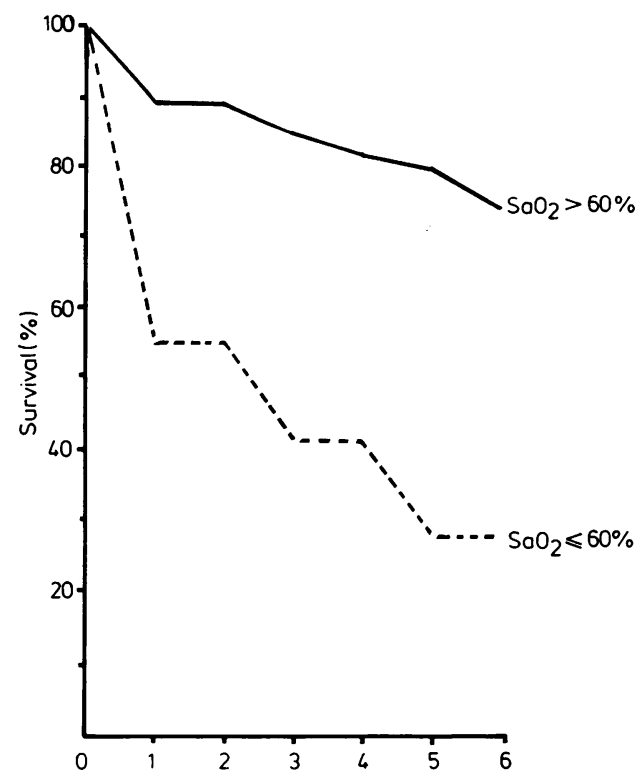

Fig. 5

Fig. 4 Six month survival of patients with haematocrit $P C V>65 \%$ and $P C V \leqslant 65 \%$. Though the difference is statistically significant $(p<0.02)$, it is not large enough to enable haematocrit to become a useful prognostic criterion.

Fig. 5 Six month survival of patients with arterial oxygen saturation $\left(\mathrm{SaO}_{2}\right)>60 \%$ and $\mathrm{SaO}_{2} \leqslant 60 \%$. Though the difference between the two groups is very obvious $(p \ll 0.001), \mathrm{SaO}_{2}$ will have a serious disadvantage if used as a prognostic criterion, because only $74 \%$ of those with $\mathrm{SaO}_{2}>60 \%$ will be alive at six months.

Inspection of the magnitude of the Student's t values (Table 3) shows that available oxygen and oxygen unloading capacity are likely to be more useful as prognostic criteria for survival at six months than the arterial oxygen saturation, arterial oxygen content, haemoglobin, or haematocrit. Fig. 1 to 5 show these conclusions in graphic form. It appears that available oxygen is the best prognostic criterion for survival at six months. Arterial oxygen saturation will have a serious disadvantage if it is used as a prognostic criterion (that is, if only patients with a low arterial oxygen saturation ( $60 \%$ and below) are selected for surgery): only $74 \%$ of patients with arterial oxygen saturations above $60 \%$ will be alive at six months, unoperated, compared with $90 \%$ for those with nor- mal available oxygen and $96 \%$ for those with normal oxygen unloading capacity. The cut off point for arterial oxygen saturation at $60 \%$ was chosen arbitrarily. If $55 \%$ and $70 \%$, however, are also chosen as cut off points, the above conclusions remain valid (see Tables 2, 3, 4). Haemoglobin and haematocrit appear to be useless as prognostic criteria. The predictive value for survival at six months for the six variables is shown in Table 4.

\section{Discussion}

This study is the first report, as far as we are aware, of the use of available oxygen and oxygen unloading capacity as prognostic criteria in children with cyano-

Table 4 Predictive value for survival at six months (for patients with complete follow up)

\begin{tabular}{|c|c|c|c|c|}
\hline \multicolumn{2}{|l|}{ Variable } & \multirow[b]{2}{*}{$\begin{array}{l}\text { Total No. } \\
28 \\
16 \\
35 \\
35 \\
40 \\
45 \\
33 \\
34\end{array}$} & \multirow[b]{2}{*}{$\begin{array}{l}\text { No. survived } \\
25 \\
15 \\
22 \\
22 \\
28 \\
30 \\
24 \\
27\end{array}$} & \multirow{2}{*}{$\begin{array}{l}\text { Predictive value } \\
89.3 \% \\
93.7 \% \\
62.9 \% \\
62.9 \% \\
70 \cdot 0 \% \\
66.7 \% \\
72.7 \% \\
79.4 \%\end{array}$} \\
\hline $\begin{array}{l}\text { Available oxygen } \\
\text { Oxygen unloading capacity } \\
\text { Haemoglobin } \\
\text { Haematocrit } \\
\text { Arterial oxygen saturation } \\
\text { Arterial oxygen content }\end{array}$ & $\begin{array}{l}>9.6 \mathrm{ml} / \mathrm{dl} \\
>2.0 \mathrm{ml} / \mathrm{dl} \\
<18.0 \mathrm{~g} / \mathrm{dl} \\
\leqslant 65.0 \% \\
>60 \% \\
>55 \% \\
>70 \% \\
\geqslant 150 \mathrm{ml} / \mathrm{l}\end{array}$ & & & \\
\hline
\end{tabular}


Table 5 Comparison of "complete follow up" and "lost to follow up" groups

\begin{tabular}{|c|c|c|c|c|c|c|c|}
\hline \multirow[t]{2}{*}{ Variable } & \multicolumn{3}{|c|}{ Complete follow $u p^{\star}$} & \multicolumn{3}{|c|}{ Lost to follow upt } & \multirow[t]{2}{*}{ Significance of difference } \\
\hline & No. & Mean & $S D$ & No. & Mean & $S D$ & \\
\hline $\begin{array}{l}\text { Available oxygen }\left(\mathrm{AO}_{2}\right) \\
\text { Oxygen unloading capacity }\left(\mathrm{O}_{2} \mathrm{UC}\right) \\
\text { Haemoglobin } \\
\text { Haematocrit } \\
\text { Arterial oxygen saturation }\end{array}$ & $\begin{array}{l}49 \\
49 \\
49 \\
40 \\
49\end{array}$ & $\begin{array}{r}9 \cdot 8 \\
0 \cdot 4 \\
16 \cdot 7 \\
51 \cdot 5 \\
74 \cdot 1\end{array}$ & $\begin{array}{r}3 \cdot 6 \\
3 \cdot 3 \\
3 \cdot 1 \\
10 \cdot 4 \\
13 \cdot 9\end{array}$ & $\begin{array}{l}30 \\
30 \\
30 \\
24 \\
30\end{array}$ & $\begin{array}{r}10 \cdot 3 \\
0 \cdot 3 \\
17 \cdot 7 \\
55 \cdot 7 \\
72 \cdot 1\end{array}$ & $\begin{array}{r}4 \cdot 2 \\
3 \cdot 9 \\
3 \cdot 5 \\
12 \cdot 0 \\
14 \cdot 0\end{array}$ & $\begin{array}{l}p>0.05 \\
p>0.05 \\
p>0.05 \\
p>0.05 \\
p>0.05\end{array}$ \\
\hline
\end{tabular}

^Follow up for six months (includes those who were not operated on during the six months after cardiac catheterisation, or those who died before operation).

t"Lost to follow up" usually the result of operation within six months of cardiac catheterisation (only four patients were truly lost to follow up). $\mathrm{SD}$, standard deviation.

tic congenital heart disease. The results appear to be very promising, and these indices would be very useful in helping the physician to decide on the urgency of cardiac catheterisation and surgery in a particular patient.

Comparison is made between available oxygen and oxygen unloading capacity and other physiological indices (arterial oxygen saturation and content, haemoglobin, haematocrit) to assess their value in prognosis. Haemoglobin and haematocrit were found to be useless as prognostic criteria. On theoretical grounds, both available oxygen and oxygen unloading capacity have a distinct advantage over arterial oxygen saturation as indices of oxygen availability to the tissues, since the haemoglobin and haemoglobin-oxygen affinity are used in addition to the arterial oxygen saturation in the calculation of these two indices. They are also expected to be superior to arterial oxygen content, since the latter does not take into account haemoglobin-oxygen affinity (p 50 in vivo). These theoretical expectations were fulfilled by our results which showed the distinct superiority of available oxygen and oxygen unloading capacity as prognostic criteria over the arterial oxygen saturation and content. As may be expected, arterial oxygen content was better than arterial oxygen saturation in prognosis because the former uses the haemoglobin in addition to the oxygen saturation.

The oxygen unloading capacity is calculated ${ }^{7}$ from the haemoglobin, arterial oxygen saturation, and the oxygen saturation of blood for a venous oxygen tension of $40 \mathrm{mmHg}$. The choice of $40 \mathrm{mmHg}$ as the venous oxygen tension for this calculation is based on the normal value for resting normal subjects. Jones $e t$ $a l .{ }^{8}$ argued on mathematical and functional grounds, that using $20 \mathrm{mmHg}$ as the venous oxygen tension instead of $40 \mathrm{mmHg}$ in the calculation of the capacity to unload oxygen will result in a more realistic index, the available oxygen. Our observation that available oxygen is a better prognostic criterion than oxygen unloading capacity is a demonstration of the validity of the theoretical arguments.
To determine whether the patients who are "lost to follow up" (largely as the result of operation) are any different from those with "complete follow up", the distribution of the available oxygen, oxygen unloading capacity, haemoglobin, haematocrit, and arterial oxygen saturation in both these groups are compared (Table 5). (The specific congenital defects in the operated and non-operated groups are shown in Table 1.) Our results show that for each of these five variables, there is no statistically significant difference between the two groups $(p>0.05)$. Thus our conclusions appear to be essentially valid despite the patients "lost to follow up" as the result of surgery.

In summary, available oxygen and oxygen unloading capacity appear to be valuable and promising prognostic criteria for children with cyanotic congenital heart disease. Like other prognostic criteria, these variables should be used in conjunction with all other clinical and laboratory data, such as growth failure, presence or absence of hypercyanotic spells, requirements for cardiac decongestive drugs, findings at cardiac catheterisation and angiography, and so on. Since available oxygen and oxygen unloading capacity by themselves are better prognostic criteria than the haemoglobin, haematocrit, and arterial oxygen saturation or content when used alone, it appears reasonable to expect that when used together with the clinical and laboratory data, they will still prove to be superior to the other three variables when they are also used in conjunction with the same data. In any case, the physician can have two new criteria, in addition to all other conventional criteria, whereby he may assess the prognosis of a child with cyanotic congenital heart disease.

\section{References}

1 Keith JD, Rowe RD, Vlad P. Heart disease in infancy and childhood. 3rd ed. New York: Macmillan, 1978: 1-9.

2 Kirklin JW. Advances in cardiovascular surgery. (Clinical cardiology monographs.) New York: Grune \& Stratton, 1973. 
3 Ravitch MM, Welch KJ, Benson CD, Aberdeen E, Randolph JG. Pediatric surgery. vol. 1. Chicago: Year Book Medical Publishers, 1979: 582-746.

4 Woodson RD, Torrance JD, Shappell SD, Lenfant C. The effect of cardiac disease on hemoglobin-oxygen binding. $\mathcal{F}$ Clin Invest 1970; 49: 1349-56.

5 Metcalfe J, Dhindsa DS, Edwards MJ, Mourdjinis A. Decreased affinity of blood for oxygen in patients with low output heart failure. Circ Res 1969; 25: 47-51.

6 Daniel A, Cohen J, Lichtman MA, Murphy MS, Schreiner BF Jr, Shah PM. The relationships among arterial oxygen flow rate, oxygen binding by hemoglobin, and oxygen utilization in chronic cardiac compensation. f Lab Clin Med 1978; 91: 635-49.

7 Oski FA. Designation of anemia on a functional basis. $\mathcal{f}$ Pediatr 1973; 83: 353-4.

8 Jones JG, Holland BM, Veale KEA, Wardrop CAJ. "Available oxygen", a realistic expression of the ability of the blood to supply oxygen to tissues. Scand $\mathcal{F}$ Haematol 1979; 22: 77-82.

9 Lichtman MA, Murphy MS, Adamson JW. Detection of mutant hemoglobins with altered affinity for oxygen. A simplified technique. Ann Intern Med 1976; 84: 517-20.

10 Lichtman MA, Murphy M, Pogal M. The use of a single venous blood sample to assess oxygen binding to haemoglobin. Br $\mathcal{F}$ Haematol 1976; 32: 89-98.

11 Rakusan $\mathrm{K}$, Marcinek $\mathrm{H}$. A quantitative analysis of oxygen release due to changes in p 50 and venous $\mathrm{p} 02$. Bull Physiopathol Respir (Nancy) 1975; 11: 269-76.

12 Stockman JA, Garcia JF, Oski FA. The anemia of prematurity. Factors governing the erythropoietin response. N Engl f Med 1977; 296: 647-50.

13 Delivoria-Papadopoulos M, Roncevic NP, Oski FA. Postnatal changes in oxygen transport of term, premature, and sick infants: the role of red cell 2,3diphosphoglycerate and adult hemoglobin. Pediatr Res 1971; 5: 235-45.

14 Wardrop CAJ, Holland BM, Veale KEA, Jones JG, Gray OP. Non-physiological anaemia of prematurity. Arch Dis Child 1978; 53: 855-60.

15 Cutler SJ, Ederer F. Maximum utilization of the life table method in analyzing survival. $f$ Chronic Dis 1958; 8: 699-712.

Requests for reprints to Professor John Tay, University Department of Paediatrics, Singapore General Hospital, Outram Road, Singapore 0316. 